\title{
LA EDUCACIÓN EN LA SOCIEDAD TRADICIONAL: PADRES, HIJOS Y MAESTROS EN EL EPISTOLARIO EL SECRETARIO
}

\author{
Education in traditional society: \\ parents, children and teachers in El Secretario
}

\section{Alicia Díaz Balado\&}

Fecha de recepción: 17/06/2016 • Fecha de aceptación: 02/12/2017

Resumen. Los epistolarios han constituido manuales de correspondencia para la difusión de las normas de la escritura epistolar. A partir de una breve presentación del epistolario El Secretario y del uso de la carta en el ámbito educativo, se analiza su contenido, centrado en la relación entre el maestro y el alumno, en la profesionalización del magisterio o en la renovación pedagógica. Los dos modelos de cartas seleccionados en el presente epistolario, A un estudiantillo y Contestación del estudiantillo, dan cuenta de las relaciones paterno-filiales -focalizadas en un modelo de correspondencia característico del siglo XIX- al tiempo que permiten un análisis fundamentalmente pedagógico. Dicho análisis posibilita la observación sobre el significado del par maestro-discípulo, las influencias pedagógicas renovadoras, así como la función de la carta como medio de expresión infantil y de control paterno en la distancia paterno-filial.

Palabra clave: Epistolario; Siglo XIx; Educación; Consejos paternos; Figura docente.

Abstract. Letter collections served as correspondence manuals for transmitting norms of epistolary writing in the $19^{\text {th }}$ century.. This article begins with a short presentation of the epistolar book El Secretario and its use in the realm of education. We analyze its content in the light of the teacher-student relationship, the professionalization of teaching and pedagogical renovation. The selected letters of El Secretario, A un estudiantillo and Contestación del estudiantillo show parent-child relationship, in the context of the epistolary narrative, while also allowing for a fundamental pedagogical analysis. This analysis offers insights into the significance of the

\footnotetext{
\& Departamento de Pedagoxía e Didáctica. Facultade de Ciencias da Educación. Universidade de Santiago de Compostela. Campus Vida. Rúa Prof. Vicente Fraiz Andón, s/n, 15782. Santiago de Compostela. España. alicia.diaz@usc.es
}

Cómo citar este artículo: Díaz Balado, Alicia. «La educación en la sociedad tradicional: padres, hijos y maestros en el epistolario El Secretario». Historia y Memoria de la Educación 9 (2019): 413-441. 
master-disciple relationship, the influence of reform pedagogy and the role played by letter-writing, both for children's self-expression and as a means of paternal control from a distance.

Keywords: Correspondence's book; Nineteenth century; Education; Parent advices; Teacher role.

\section{INTRODUCCIÓN}

Los epistolarios - cuya amplia tradición textual e histórica se prolonga desde el siglo XIX hasta el siglo xx - constituyen manuales de correspondencia destinados a la difusión de las normas de la escritura epistolar. Según Serrano, ${ }^{1}$ ya estos habían gozado de divulgación en España durante la Edad Moderna; un ejemplo de ello se halla en la venta de aproximadamente 2000 ejemplares del Estilo y formulario de cartas familiares, de Jerónimo Paulo de Manzanares, mientras que, en 1622, el Secretario de señores de Gabriel Pérez del Barrio había obtenido un eco semejante. En menos de un siglo, desde 1547 hasta 1639, la edición y reedición de obras de este tipo confirmaron esta difusión.

Desde fines del siglo xix y principios del siglo xx, indica Sierra que estas obras devienen de representar un símbolo de distinción con un elevado precio a introducirse en el tejido social y,

aunque en un principio fueron obras fundamentalmente destinadas a las gentes de letras y a los profesionales del mundo de lo escrito (a los secretarios, a los escribanos y notarios, etcétera), a medida que la necesidad de escribir cartas fue impregnando todas las parcelas de la sociedad y nuevas clases sociales ascendieron a su práctica [...] el manual se fue popularizando y varió su materialidad y su contenido para amoldarse a las características de su nuevo público. La demanda de estos nuevos lectores sacó al libro de las estanterías de los eruditos, clérigos y pudientes, y lo llevó a la calle, a los puestos ambulantes y a los quioscos. ${ }^{2}$

\footnotetext{
${ }^{1}$ Carmen Serrano, "Secretarios de papel”: Los manuales epistolares en la España Moderna (siglos XVI-XVII)», en Cinco siglos de cartas. Historia y prácticas epistolares en la época moderna y contemporánea, eds. Antonio Castillo y Verónica Sierra (Huelva: Universidad de Huelva, Servicio de Publicaciones, 2014), 88.

${ }^{2}$ Verónica Sierra, «¡Cuidado con la pluma! Los manuales epistolares en el siglo xx», Litterae: Cuadernos de cultura escrita 3, no. 2 (2003): 283-284.
} 
Dicha autora señala varios títulos de manuales epistolares popularizados en el siglo xx, citados a continuación. La propia Sierra, en 2016, extiende su análisis a los usos y funciones de la escritura epistolar en períodos de reclusión o en situaciones de guerra, focalizado tanto en el ámbito privado de las relaciones personales como en el contexto de aquellas cartas dirigidas a la autoridad pública, remitidas para solicitar favores o reconocimiento de derechos. ${ }^{3}$ En 1938, en una situación de guerra, Oscanio, pseudónimo de José Pardo Asso, publica en Zaragoza El soldado y el amor. Cartas emotivas (sentimiento e ilusión), para alentar a las mujeres a desempeñar la función de madrinas de guerra; en este sentido, el barcelonés Bartolomé Bauzá editará en 1943 Cómo debe escribir sus cartas la mujer, escrito por Harmency, y también durante la década de los años 40 la Editorial Cisne ofrece una colección de cuatro manuales epistolares titulados, respectivamente, 3 Nuevos Manuales de cartas, Secretario de los amantes (Novísimo Correo del amor), Cartas de amor, de odio y de ternura, y Declaraciones de amor y arte de enamorar, tras el éxito que había conseguido con la publicación de 200 manuales epistolares.

El epistolario había adquirido difusión y popularidad en el siglo XIX. En este sentido, Castillo remite a la relevancia del aprendizaje a partir de la escritura y de los documentos cotidianos, entre los que se hallaba el manual de correspondencia. Para ilustrar esta significación, el autor se hace eco del ejemplo de un maestro o "profesor de primeras letras», que se anuncia el 1 de enero de 1874 en el periódico Crónica Meridional, el cual, tras presentarse como antiguo alumno de la Escuela Normal Central, se ofrece para dar lecciones a domicilio o en su casa, para acompañar a los escolares al colegio, para acudir a misa y también para escribir cartas. ${ }^{4}$ En este contexto, Gold revela que, aunque la abundancia de material epistolar en España se ve reducida, en comparación con el acervo de otros países europeos, en el siglo XIX

para quienes escriben libros de texto para universidades e institutos de segunda enseñanza, las cartas son un dechado de es-

\footnotetext{
${ }^{3}$ Verónica Sierra, Cartas presas. La correspondencia carcelaria en la Guerra Civil y el Franquismo (Madrid: Marcial Pons, Editorial Complutense, 2016).

${ }^{4}$ Antonio Castillo, «"Me alegraré de que al recibo de ésta ...”. Cuatrocientos años de prácticas epistolares (siglos XVI a XIX)», Manuscrits 29 (2011): 19-50.
} 
tilo y un tesoro evolutivo del desarrollo y uso del lenguaje, a la vez que una fuente de sabiduría sobre las acciones humanas. La inclusión de los textos de cartas selectas en tales libros serviría para montar una antología de elocuencia castellana con claros fines didáctico-morales. ${ }^{5}$

Los epistolarios se estructuran en una serie de modelos de cartas que hoy en día ofrecen una perspectiva de las relaciones y de los valores predominantes en un tiempo y en un espacio determinados. En la actualidad, el epistolario representa un instrumento de primer orden para el análisis de la sociedad en la que se origina.

En la medida en que el epistolario respeta y ofrece un espejo del orden establecido, se constituye como un recurso educativo de interés en ámbitos diversos. Por ejemplo, entre los tantos epistolarios destinados a la actividad comercial, José Eusebio Gómez de Mier publicó en 1854 El comerciante español ó epistolario comercial, en cuyo extenso título se señala su profusión de contenidos. ${ }^{6}$ Curiosamente, Escolano se hace eco de la utilización de la carta comercial para el ejercicio de la denominada escritura en carta o en proceso, recogida por Narganes de Posada en 1809:

El tardoilustrado Narganes de Posada, en sus Tres cartas sobre los vicios de la Instrucción Pública en España, obra aparecida en 1809, describió bien los métodos que seguían las escuelas en la transición del Antiguo Régimen al liberalismo en la materia que nos ocupa. "Cuando ya saben leer de corrido la letra de molde, (los niños) pasan a leer la manuscrita, y esto se llama

\footnotetext{
${ }^{5}$ Hazel Gold, «Una postdata imprescindible: cartas y epistolarios en el canon literario del siglo XIX», en La elaboración del canon en la literatura española del siglo XIX: II Coloquio de la Sociedad de Literatura Española del Siglo XIX (Barcelona, 20-22 octubre de 1999), eds. Luis F. Díaz Larios, Jordi Gracia, José M. ${ }^{a}$ Martínez Cachero, Enrique Rubio y Virginia Trueba (Barcelona: Universitat, Promociones y Publicaciones Universitarias, 2002), 187.

${ }^{6}$ Se ofrece el título completo del epistolario con su referencia: José Eusebio Gómez de Mier, El comerciante español ó epistolario comercial con modelos de contabilidad y documentos mercantiles, la traducción de las frases de difícil inteligencia, una fraseología infantil en español y alemán, un vocabulario de los términos más usados en el comercio y nomenclatura de los artículos más corrientes, en ambas lenguas, las abreviaturas más usuales en la correspondencia española y un suplemento en latín, alemán y español conteniendo las principales drogas medicinales (Hamburgo: Imprenta de J.J. Nobiling, 1854). Edición digitalizada por la Universidad Complutense de Madrid y disponible en https://babel.hathitrust.org/cgi/pt?id=ucm.5325492587;view=1up;seq=9/
} 
leer en carta o en proceso: los libros elementales para éste son las cartas, las más veces de comercio y que los chicos se procuran en sus casas, o el expediente de algún pleito de su familia, o que les presta el escribano». ${ }^{7}$

En la presente ocasión, los textos que serán objeto de un análisis pedagógico, conforman un conjunto de cartas extraídas del epistolario El Secretario, publicado por la editorial burgalesa Hijos de Santiago Rodríguez. ${ }^{8}$ Siguiendo a Escolano, la editorial de referencia constituye una de aquellas ubicadas fuera de las capitales de Madrid y Barcelona, que aglutinaron una buena parte de estas empresas en sus inicios. Existió también una red de libreros, editores e impresores castellanos y aragoneses, «donde más se enraizó la tradición editorial y la industria y la cultura del libro». ${ }^{9}$ De hecho, el catálogo-recuerdo de 1925 de Hijos de Santiago Rodríguez contiene 161 páginas centradas en los libros escolares y material pedagógico. El lema de la editorial, escogida por el fundador en sus inicios, fue «La escuela redime y civiliza». A un nivel extenso,

los iconos, lemas y demás elementos emblemáticos configuraron las señas de identidad de cada editora escolar. Motivos y temas que aluden a la infancia, a las letras y a las ciencias, a las luces y a la civilización, al progreso y al triunfo de la sabiduría y a la acción regeneradora de la escuela podían ser analizados desde la semiología como signos de una nueva cultura material de la enseñanza y como exponentes del ideario y de la autoimagen de las primeras tradiciones editoriales asociadas al mundo de la educación. ${ }^{10}$

Afirma Sánchez Redondo que la editorial Hijos de Santiago Rodríguez, hacia la década de los sesenta aún conservaba su relevancia en cuanto a la edición de textos para la Educación Primaria, junto con Dalmáu o, en mayor medida, las editoriales Magisterio Español o Escuela

\footnotetext{
${ }^{7}$ Agustín Escolano, «Los manuscritos escolares», en Historia Ilustrada del libro escolar en España, ed. Agustín Escolano (Madrid: Fundación Germán Sánchez Ruipérez, 1997), 347.

${ }^{8}$ El Secretario (sin año de edición). Burgos: Hijos de Santiago Rodríguez.

9 Agustín Escolano, «Libros para la escuela. La primera generación de manuales escolares», en Historia Ilustrada del libro escolar en España, 23.

${ }^{10}$ Escolano, «Libros para la escuela», 27.
} 
Española. ${ }^{11}$ Badanelli y Mahamud la sitúan, junto con Edelvives, publicando prácticamente durante todo el período comprendido entre 1959 y 1975, de lo que son un ejemplo sus manuales de lectura. Manuel Antonio Arias, María Baldó, Enrique Basabe o Josefina Bolinaga figuraron entre la nómina de autores de la editorial, que había sido fundada en Burgos en 1850. ${ }^{12}$

Los epistolarios se enmarcan en la tradición ilustrada señalada por Escolano que, más allá de las primeras letras, fomentó la edición de textos de matemáticas, náutica, comercio, agricultura y otras artes o ciencias relacionadas con la enseñanza técnica, así como folletos y cartillas para la difusión de conocimientos de utilidad dentro y fuera de la escuela. ${ }^{13}$ En el siglo xx se mantuvo su pervivencia, así como la de los manuales de cartas en una sociedad regida por un sistema relacional jerárquico, donde los modelos de la escritura disponibles venían a resolver el amplio acervo de cuestiones a las que fue necesario dar respuesta a través del establecimiento de una correspondencia basada en el civismo y en la urbanidad, según los cánones respetuosos del orden social presidido por la alta burguesía conservadora. En palabras de Martínez Cuadrado, fue en las clases medias donde el propósito de recatolización dio excelentes resultados entre el período comprendido entre 1875 y 1931, impulsado por la tarea de la Iglesia católica de frenar su proceso de desreligación porque «la cultura tradicional católica y populista había dominado la imagen del mundo, los ocios y los mitos de la mayoría de las clases sociales hispánicas hasta por lo menos la primera mitad del siglo XIX». ${ }^{14}$ A partir de las revoluciones políticas de 1854, 1868 y 1873 , «entre las clases medias y burguesas la dispersión cultural se acompaña de multitud de tendencias», y una parte de la burguesía se incorpora a la lucha en el ámbito religioso, político y económico contra la Iglesia católica —época de la desamortización-, así como en el de las creen-

\footnotetext{
${ }^{11}$ Carlos Sánchez-Redondo, "Política e ideología en los libros de lectura escolares en la escuela primaria de los años sesenta», en El libro escolar, reflejo de intenciones políticas e influencias pedagógicas, ed. Alejandro Tiana (Madrid: UNED, 2008), 115-133.

12 Ana María Badanelli y Kira Mahamud, «Entre la ruptura y la continuidad de esquemas socioemocionales en los libros de lectura», Historia y Memoria de la Educación 2 (2015): 125-160.

${ }^{13}$ Agustín Escolano, «Textos científicos y didácticos utilizados en las escuelas técnicas en la segunda mitad del siglo xvIII y principios del XIX», Historia de la Educación 4 (1985): 385-395.

${ }_{14}$ Miguel Martínez Cuadrado, La burguesía conservadora (1874-1931) (Madrid: Alianza, 1973), 533-534.
} 
cias vitales, con la expansión del liberalismo entre 1820 y $1874 .{ }^{15}$ Pero, aun así, en la época la burguesía se diversificó entre el elitismo racionalista y liberal y el elitismo nacionalista y antiliberal, hacia el que tienden, con los matices procedentes, los textos del epistolario seleccionados para el presente análisis.

En su extensa reflexión acerca de las antologías de los libri di lettere en el siglo Xvi, en cuyo contexto Ludovica Braida sitúa el fenómeno editorial de los manuales epistolares, dirigidos a «jóvenes aristócratas iniciados en los estudios humanísticos, profesionales necesitados de síntesis en temas y disciplinas que no conocían o, incluso, hombres poco alfabetizados pero ávidos de enfrentarse a la lectura de los libros de divulgación", ${ }^{16}$ se recoge que la variedad de textos incluidos en las mismas permitía responder a las expectativas de un público culto que se acercaba a unos

libros de lectura apetecibles por la amplitud de relaciones e intercambios personales de los que eran la máxima expresión [...]. Una reflexión recorre muchas antologías epistolares: el rol que desempeña la escritura y, en particular, la escritura de cartas como elemento de distinción en las relaciones sociales. ${ }^{17}$

En la medida en que el epistolario muestra y reproduce el orden establecido, constituye un recurso educativo susceptible de ser examinado con singular interés en sus diferentes ámbitos de utilización.

Las cartas objeto de interés muestran una relación jerarquizada entre padres e hijos, percibida en el contexto de un orden social establecido y reflejado en un conjunto epistolar, cartas en las cuales tanto las relaciones personales, las marcadas por la autoridad o también aquellas comerciales discurren por cauces rígidamente heredados que a un tiempo reproducen.

\footnotetext{
15 Martínez Cuadrado, La burguesía conservadora (1784-1931), 534.

16 Ludovica Braida, «Los libri di lettere en el siglo xvi. Un género editorial entre el disenso religioso y la difusión del "buen vulgar" " en Cinco siglos de cartas. Historia y prácticas epistolares en las épocas moderna y contemporánea, 100. En lengua vulgar, los libri lettere poseerían su origen a partir de la relevante presencia de antologías epistolares de autores clásicos y humanísticos en latín, publicados a raíz de la difusión de la imprenta.

17 Braida, «Los libri di lettere en el siglo XVI», 101.
} 
Aun considerando el contexto epistolar en el marco tradicional de la España católica y tradicional, como textos dirigidos a un público burgués, es nuestro propósito plantear la interrogante que sigue a continuación. ¿Pervive una evocación de relativa modernidad en el estilo educativo conservador de los modelos seleccionados para el análisis? ¿Es posible, en la medida en que el contenido de las cartas analizadas sigue una línea fundamentalmente educativa, identificar en la redacción epistolar una cierta bifurcación desde la pedagogía tradicional, en consonancia con la irrupción y desarrollo de una nueva metodología, propia de la pedagogía progresista con sus nuevos roles para maestro y alumno? Es en esta dirección en la cual procederá el análisis epistolar de las cartas seleccionadas.

\section{LA CARTA, RECURSO EDUCATIVO FORMAL E INFORMAL}

El Secretario, la obra que se toma en consideración para el presente análisis, es un manual de utilidad práctica con una evidente intención instructiva y educadora en un sentido extenso. El Secretario se incluye en un amplio conjunto de publicaciones que responden al proceso, mencionado por Gómez Hernández e iniciado en el siglo XIX español, dirigido por el Estado y contextualizado entre las luchas de las ideas absolutistas y liberales, cuando paulatinamente la noción de ciudadano va sustituyendo a la noción de súbdito, en tanto que el ideal de que la soberanía reside en el pueblo puede interesar a este por la alfabetización, la educación y la cultura y reflejarse en el desarrollo de la prensa y la literatura popular bajo diversas formas, así como en el interés de fomentar la lectura pública, "antes que en las bibliotecas, en gabinetes de lectura, sociedades y librerías». ${ }^{18}$ Señala Gómez Hernández que el ciudadano se constituye «sujeto de derechos, parte de la "nación", involucrado en su propio futuro»; ${ }^{19}$ la finalidad instructiva de El Secretario, por lo tanto, se plasma como instrumento que capacita para la resolución de la problemática diversa a que el lector debe hacer frente en las múltiples facetas de la vida cotidiana.

\footnotetext{
18 José Antonio Gómez Hernández, «La preocupación por la lectura pública en España: las bibliotecas "populares". De las Cortes de Cádiz al plan de bibliotecas de María Moliner», Revista General de Información y Documentación 2, no. 3 (1993): 56.

19 Gómez Hernández, «La preocupación por la lectura pública en España», 56.
} 
Para Olmos, el conjunto de lecturas dirigidas a las clases populares pudo haber sido amplio, ya que a partir del análisis de colecciones públicas y privadas de libros, se ha constatado que fue rasgo notable de su comportamiento lector la voluntad de instrucción, al menos desde 1800, al haberse hallado en los hogares biografías de científicos, obras históricas o enciclopedias. ${ }^{20}$

Acerca de la utilización de la correspondencia epistolar en el aula, para Sierra ${ }^{21}$ ha quedado constancia en los múltiples testimonios orales y en los documentos presentes en las escuelas primarias durante los años 30 y 40 del siglo xx del recurso a modelos a partir de los cuales los maestros enseñaban a escribir cartas al alumnado; una actividad para la que se emplearon también las lecturas de manuscritos o los manuales epistolares dirigidos a los escolares.

Como parte de este amplio conjunto de publicaciones, la presente obra representa un vehículo para el análisis de la función educativa y socializadora del manual epistolar, en tanto Sierra ha destacado su función pedagógica, adoctrinadora, moralizante o propagandística.$^{22} \mathrm{El}$ citado epistolario no representa, propiamente dicho, un manual epistolar para la infancia, ya que tampoco responde a la totalidad de las características de las que se hace eco Sierra, entre las que se hallan la consecución de una buena competencia en la redacción o difusión de los valores morales, religiosos y patrióticos para la infancia y la constatación de la importancia de la lectura en el ámbito educativo, así como la iniciación en el arte epistolar. ${ }^{23}$ El Secretario contiene modelos de cartas que aportan pautas para la conducta, necesarias para el desarrollo de las estimadas como buenas relaciones en los diferentes ámbitos de la sociedad; un manual no exento de un claro objetivo pedagógico en cuanto a la transmisión de valores o incluso de competencias instrumentales que la función epistolar precisó en la sociedad española, por lo que, aunque no constituye un manual escolar, sí comparte con ellos la inicia-

\footnotetext{
${ }^{20}$ Miguel Á. Olmos, «Sobre lectores “populares” y lectura común en España (1870-1936)», Dicenda. Cuadernos de Filología Hispánica 22 (2004): 183-199.

${ }^{21}$ Verónica Sierra, “"As Cartas e a Escola” los manuales epistolares para niños en la España del siglo xx», História da Educaçao 16, no. 2 (2004): 59-77.

${ }^{22}$ Verónica Sierra, Aprender a escribir cartas. Los manuales epistolares en la España contemporánea (1927-1945) (Gijón: Trea, 2003).

${ }^{23}$ Sierra «"As Cartas e a Escola” los manuales epistolares para niños en la España del siglo xX».
} 
ción al arte epistolar o la consecución de una buena competencia en la redacción o difusión de los valores constitutivos de la clasificación precedente. El manual El Secretario distribuye sus contenidos en diferentes secciones, bajo la amplia temática de cartas familiares, memoriales y comerciales y, según declara en su prólogo, pretende ofrecer una respuesta para las variadas situaciones en las que la vida puede situar a los individuos:

Quien no sabe cambiar impresiones con sus iguales en forma conveniente, no podrá lograr bienestar alguno. [...] Aspiramos que este librillo resulte de verdadera utilidad para todos, y confiamos en que el público ha de responder á la delicadeza con que hemos procurado confeccionarlo. ${ }^{24}$

Alguna de las cartas incluidas en El Secretario incorporan en el encabezamiento o bien en su remate la fecha correspondiente a la última década del siglo XIX, y si bien El Secretario pudo ser susceptible de un uso intencional dentro de las aulas, su fin más directo semeja estar relacionado, antes bien, con la presentación al público de las variadas soluciones que las relaciones personales, sociales y profesionales exigieron en múltiples circunstancias, tal y como se indicó en líneas anteriores. Pese a ello, el estudio de sus textos resulta de indudable interés para el análisis de las relaciones entre padres, estudiantes y maestros en la sociedad tradicional de la Restauración española, así como sobre determinados aspectos educativos y sociales de ese tiempo. Con independencia de la fecha de edición del manual objeto de análisis, es posible afirmar que su finalidad formadora guarda coherencia con el modelo relacional de la sociedad correspondiente con el período histórico fechado.

\section{EL ANÁLISIS EPISTOLAR: LAS INFLUENCIAS PEDAGÓGICAS EN SUS CONTENIDOS}

Las dos cartas seleccionadas, "A un estudiantillo» $\mathrm{y}$ "Contestación del estudiantillo», representativas de la correspondencia entre padres e hijos ofrecida por El Secretario, se hallan incluidas bajo los respectivos títulos de las secciones «De padres a hijos» $\mathrm{y}$ «De hijos a padres», co-

${ }^{24}$ El Secretario, 6. 
rrespondientes al apartado de las cartas familiares. Ambas cartas son el punto de partida para el análisis de los contenidos centrales constitutivos de interés histórico-educativo dado que el modelo de relación epistolar se fundamenta sobre los consejos de los padres y la respuesta del escolar.

La estructura del libro incluye un prólogo subtitulado La importancia de la carta, seguido por el apartado Cartas Familiares, con recomendaciones sobre el estilo y la forma en la redacción. En adelante, las páginas dan paso al contenido de los apartados que desarrollan las Cartas de padres a hijos y de hijos a padres —en los que se insertan los dos modelos analizados-, De hermanos, de esposos, Maestros y discípulos, Para amigos y parientes y Amatorias con sus correspondientes contestaciones, así como Correspondencia de amantes ya relacionados y De etiquetas y suplicatorias con sus contestaciones, Memoriales y, por último, Comerciales. Otras cartas derivadas de los oportunos apartados que guardan relación con aquellas seleccionadas para el análisis son las dirigidas «A un buen estudiante», "A un suspenso en exámenes» con sus contestaciones, «A un joven, aconsejándole», «A un discípulo aventajado» y también «A un maestro».

La carta ha sido analizada como un medio para la participación en procesos de lectura y escritura al margen de aquellos planificados por el docente en el aula, aunque esta pueda constituir a su vez un instrumento o recurso constitutivo para tal aprendizaje. Judith Kalman alude al carácter de los eventos de la lectura y la escritura en la vida cotidiana, dispuestos con fines comunicativos, por lo que suponen «importantes contextos para la apropiación de los diversos usos de la cultura escrita», en los que «su significado abarca tanto las acciones de los actores sociales como los vínculos entre ellos». ${ }^{25}$ Así, la intencionalidad comunicativa, el contexto y los propios participantes caracterizan a la carta como medio de expresión, con independencia de la actividad planificada para la enseñanza y el aprendizaje de la lengua escrita en el aula.

En el núcleo de esa intencionalidad comunicativa, entre la suerte de recomendaciones paternas en los textos que nos ocupan, destacan aque-

\footnotetext{
${ }_{25}$ Judith Kalman, «El acceso a la cultura escrita: la participación social y la apropiación de conocimientos en eventos cotidianos de lectura y escritura», Revista Mexicana de Investigación Educativa 17, no.8 (2003): 42-43.
} 
llas dirigidas hacia la vigilancia del respeto y la consideración debidas al maestro responsable de guiar la educación, quien representa un personaje central en ambos textos. Porque los modismos y las expresiones empleadas, representativas de las ideas subyacentes en cada carta, contextualizan una sociedad tradicional con los papeles establecidos, categorizada de tal forma que tanto en las palabras paternas como en las filiales destaca la figura docente en el sujeto de un mencionado maestro «simbólico», coherente con el fondo de un bosquejado escenario.

Los contenidos de ambas cartas se complementan entre sí, de manera que, a las peticiones paternales de estudio, aplicación y rectitud, el hijo responde con ductilidad y acatamiento de los consejos.

El texto paterno emplea un estilo afectuoso, en un discurso próximo a la pedagogía de la emulación que no persigue necesariamente el desarrollo personal del estudiante; si bien, en la línea de la disciplina en la que se integran sus consejos de constancia en los estudios, no se advierte rigidez ni autoritarismo. El hijo responde a los padres con una actitud adaptada a la línea seguida por estos. La expresión «Yo seguiré vuestros consejos», viene a resumir una actitud dócil hacia su papel en la vida, tanto en su primera juventud como en la futura colocación que lo sitúe en el escenario social. Las palabras «De mis hermanitas me acuerdo también muchísimo [...]. Dénlas muchos besos, con recuerdos á los parientes, amigos y criados», evidencian su procedencia familiar medianamente acomodada; un origen, con toda probabilidad, similar a la de sus compañeros de internado.

Así como se presenta un vínculo idealizado en la correspondencia entre padres e hijo, también la mirada que los textos ofrecen del docente continúa esta misma dirección. El maestro retratado en las palabras del estudiante es una figura amable o afectuosa con el escolar, merecedora de respeto por sus actos, pero también por lo que representa, quien, sin apartarse de su rol en la sociedad tradicional, denota poseer una preparación que lo vincula con ciertas y características novedades pedagógicas que se inician y desarrollan a caballo de los siglos XIX y Xx. Porque, como afirma Escolano, la cultura escolar inspirada en la nueva educación no consistió en la síntesis de la traslación de postulados y orientaciones activistas, así como tampoco en el precipitado instrumental de las experiencias científico-técnicas promovidas por la nueva co- 
rriente, sino que fue el resultado de complejos procesos de interacción entre la cultura empírica del colectivo de enseñantes, con sus tradiciones e innovaciones generadas en la misma práctica como ensayos orientados al cambio. ${ }^{26}$

\section{La carta enviada por los padres: «A un estudiantillo»}

El texto de la carta enviada por los padres retrata el perfil del buen escolar sobre el fondo de un orden social determinado: plantea la necesidad del hijo de salir de la villa o pequeña población para crearse un porvenir y «hacer carrera», por encima de la aflicción que a la familia le produce su distanciamiento físico. La ausencia del hijo se asume como una oportunidad de prosperidad o ascenso social, y con tal fin se realizó la cuidadosa elección del internado que será su lugar de estudio y vivencias futuras.

Durante un largo período temporal, aproximadamente a partir del desarrollo de la escuela como institución hasta décadas bien recientes, la aquiescencia o conformidad de los padres hacia la actuación del maestro presidió las relaciones escolares, resultado, en cierta medida, del crédito social del que gozaba el docente. El maestro se hacía merecedor del respeto social, pues su autoridad residía en la transmisión y en la administración del saber, función refrendada por una sociedad sensiblemente deficitaria en materia educativa. Históricamente, la relación establecida entre maestro y discípulo ha respondido a las demandas del sistema de socialización, en las que los educadores obraron como agentes secundarios, encargados de ratificar, ampliar o diversificar los aprendizajes realizados en la familia, entendida esta como grupo social primario. En la presente carta, la consecución de los buenos logros escolares y del deber de la disciplina parecen ser objetivos comunes compartidos por padres y maestro.

A lo largo del texto se hallan numerosos ejemplos del significado y de la utilidad que la aplicación en los estudios ofrece para el éxito en la vida a través de frases como las señaladas seguidamente. Los padres se refieren, también, a las necesarias demandas de respeto que la figura

\footnotetext{
${ }^{26}$ Agustín Escolano, «La recepción de los modelos de la Escuela Nueva en los manuales de comienzos del siglo xx», Historia de la Educación 25 (2006): 317-340.
} 
del maestro exige, cuestión que incluso se prioriza sobre la voluntad de un exitoso rendimiento escolar:

Ya tuvimos buen cuidado en elegir tu internado en buenas condiciones; sabemos que esos buenos señores te cuidarán con esmero, te consolarán, te dirigirán bien en tus estudios. [...]. Queremos que estudies como hasta aquí: con fe, constancia y gusto; con eso nos basta, y nada te importe si cumples con tales condiciones precisas al bueno, el que no pudieras aspirar en su día á notas, á premios, á recompensas superiores. Si las luces de tu inteligencia te permiten hacer brillantes exámenes, sea muy enhorabuena; tus padres se llenarán de regocijo; si esto es superior á tus fuerzas, nada te apure; con serenidad perfecta recibiremos lo que venga, siempre que sepamos has cumplido con tu deber, haciendo cuanto la voluntad firme, constante, decidida, ordenan. Lo que nunca te tolerarían tus padres es lo que de ti no podemos esperar: faltas de respeto, de consideración, de amor á quien te dirige; si llegas á amarle, le respetarás y considerarás; que la ley de Jesucristo, que es el principio de la vida eterna, en el amor está fundada. ${ }^{27}$

Los padres aconsejan y ofrecen directrices explícitas en la relación de su hijo con el maestro. El rol docente supone la existencia del rol del alumno, porque la existencia del primero carece de sentido sin la presencia del estudiante, pues para atender a las necesidades formativas del alumnado, la sociedad se dotó de profesionales de la enseñanza. Para Steiner, el conjunto maestro-discípulo no se limita a los ámbitos de la religión, la filosofía o la literatura; es un hecho de la vida entre generaciones, que resulta inherente a toda formación y transmisión. Los maestros contribuyen al rol endoculturador, pues protegen e imponen la memoria de generaciones anteriores. ${ }^{28}$

¿De qué forma se trasladan a las generaciones jóvenes los saberes o el conjunto de conocimientos culturales? O, en referencia a la expresión anterior, ¿cuál es la forma de transmisión de la memoria a las generaciones posteriores? Explica Pérez-Díaz, en relación a los mecanismos de

${ }^{27}$ El Secretario, 12-13.

${ }^{28}$ George Steiner, Lecciones de los maestros (México: Siruela, Fondo de Cultura Económica, 2004). 
comunicación entre discípulos y maestros, que las formas de transmisión y aprendizaje son diversas, pues el aprendizaje se produce por imitación de los gestos intelectuales, a través de

sus modos de razonar y de expresarse, su uso de la metáfora, el estilo de su tratamiento del material empírico, las connotaciones emocionales de su opinión sobre las personas, la generosidad o mezquindad de su juicio, la amplitud o estrechez de su horizonte, su impaciencia o su calma, su disposición a decir sí o no a determinados estímulos, y la evocación de sus experiencias, que el discípulo tendrá que reconstruir combinando sus palabras explícitas, sus alusiones y sus silencios. ${ }^{29}$

Una responsabilidad manifiesta que se le concede al maestro, docente o profesor, pues, como indica Morales, el maestro enseña saberes y técnicas, pero fundamentalmente interviene en el espacio más amplio y hondo de la vida. Y será en ese espacio vital extenso donde se adquieren y aprenden, junto con las primeras letras o el cálculo, también las actitudes y las creencias, las normas, los valores y la disciplina. ${ }^{30}$

Fernández Pombo, citado por Javier Barquín, recoge la revisión de la figura del profesor a través de la literatura del siglo XIX, y resume una serie de atributos que luego han pasado a ser característicos de la función docente, entre los que, entre otros, se encuentran la vocación, la bondad natural o una escasa formación profesional; para otros de ellos, su vigencia se habría perdido, como el castigo físico. ${ }^{31}$ Andrea Alliaud abunda en estos atributos, que al fin son construidos socialmente,

¿Cuáles son los atributos que aparecen «naturalmente» adosados? ¿El amor a los niños, la vocación por la enseñanza, el «dar todo de sí», sin esperar recompensas, es decir el sacrificio?

\footnotetext{
${ }^{29}$ Víctor Pérez-Díaz, «Maestros y discípulos. Algunas causas culturales e institucionales de la debilidad de la universidad española contemporánea», ASP Research Papers 106 (a) (2012): 2.

${ }^{30}$ José Morales, «Maestros y discípulos», SCHRIPTA THEOLOGICA 37, no. 2 (2005): 607-215.

${ }^{31}$ Javier Barquín, «La investigación sobre el profesorado. Estado de la cuestión en España», Revista de Educación 306 (1995): 25. La tesis doctoral de Alejandro Fernández Pombo, titulada El profesor en la sociedad española del siglo XIX a través de la literatura, publicada en 1984, incorpora los atributos mencionados.
} 
Más allá de la situación y posición social (diferente entre el maestro, el médico, el filósofo o el arquitecto, pero, de algún modo relacionado), parecería existir cierto tipo de características comunes que definen «al» maestro, al margen de un sinfín de individualidades. Tales rasgos, que conforman una especie de «modelo» — compartido por los maestros y la sociedad en su conjunto-, adquieren un fuerte grado de legitimidad por aparecer naturalmente ligada a una determinada condición social. [...] Una vez aceptada la existencia de ciertos elementos «comunes» entre una diversidad de acciones, sería oportuno reflexionar sobre el carácter de aparente naturalidad que de inmediato se les atribuye. En este sentido, es posible adelantar que ese trasfondo común, generador de prácticas en individuos que ocupan posiciones semejantes en la estructura social (los maestros en nuestro caso), que los constituye en tanto tales al tiempo que los diferencia «legítimamente» de otros grupos sociales, es en realidad socialmente adquirido e históricamente producido. ${ }^{32}$

En relación a la referida educación sobre las actitudes, en la carta que se examina, el maestro se erige como remedo de los padres, de manera que estos se identifican por completo con la labor de mentor del docente, al que los padres le atribuyen un sentido de consejero y modelo de vida para la juventud. En su conjunto, las intenciones intrínsecas de la carta reflejan un modelo educativo global a seguir por parte del escolar, que deberá conducirse como «buen hijo, buen religioso, buen discípulo, buen amigo, buen ciudadano», ${ }^{33}$ guiado por la gratitud y obrando en primer lugar con condescendencia hacia sus compañeros de pupitre.

En el campo de la formación actitudinal, las advertencias y recomendaciones paternas expresadas en la presente carta discurren en la línea del respeto reverencial hacia la figura del maestro. El maestro, guía y autoridad, es poseedor de las competencias relacionadas con la labor socializadora que conforma buenos ciudadanos, pero también es transmisor de los aprendizajes instrumentales en una sociedad ex-

\footnotetext{
32 Andrea Alliaud, Los maestros y su historia (Buenos Aires: Granica, 2007), 25-26.

33 El Secretario, 13.
} 
tendidamente analfabeta. Barreiro no prescinde de señalar el papel del maestro como intermediario y recuerda el sentido de las palabras durkheimianas en la afirmación de que la propia enseñanza comenzó con la predicación, en una clara alusión al histórico monopolio de la Iglesia respecto de las tareas docentes, cuando en el pasado sacerdotes y frailes se postularon como intermediarios de los textos que fueron puerta o acceso al conocimiento. ${ }^{34}$

La redacción epistolar aparece intercalada de expresiones devotas y alusiones a la doctrina religiosa, en las que se apela a la confianza en Dios o a la ley de Jesús, «la confianza en Dios y el intento noble que en nuestra resolución nos guía, nos alientan y fortifican», ${ }^{35}$ reflejo de una sociedad católica y tradicional en la que las referencias cristianas aún aparecen en los documentos administrativos y también en la correspondencia epistolar más o menos formal. De hecho, la injerencia de la religión en la escuela se deja ver explícitamente en la simple alusión por parte del escolar a los rezos en la clase.

Con posterioridad a la labor inicial del representante religioso en la transmisión del aprendizaje, la evolución de la sociedad hacia posiciones laicas, unida a la necesidad de la profesionalización de la enseñanza propició que, andando el tiempo, la institucionalización del magisterio en la sociedad española atravesara por diversos períodos. Así es que, con anterioridad a 1838, como indican Román y Cano, la formación teórica del maestro en España fue casi inexistente, sujeta a una capacitación de carácter gremial, en la que el ayudante o pasante adquiría un pobre conjunto de conocimientos en el ejercicio del oficio junto a un maestro ya en ejercicio. Su preparación comenzó a ser refrendada en una línea profesionalizadora con la desaparición de su carácter gremial, cuando en 1839 se creó en Madrid la primera Escuela Normal de España bajo la denominación del Seminario Central de Maestros del Reino. Entre el conjunto del alumnado que se formaba durante dos cursos, se preveía la asistencia, con cargo a las Diputaciones Provinciales, para completar su formación, de dos alumnos por provincia, que que-

\footnotetext{
${ }^{34}$ Herminio Barreiro, «Orixes institucionais da educación pública europea», Sarmiento. Revista Galega de Educación 110 (2007): 117-129.

35 El Secretario, 12.
} 
daban así facultados para la posterior apertura de Escuelas Normales en sus circunscripciones de origen. ${ }^{36}$

\section{La respuesta epistolar del hijo: «Contestación de un estudiantillo»}

En el precedente modelo epistolar dirigido al escolar destaca la interiorización de los méritos de obediencia y civilidad que el destinatario, en su respuesta, asume como suyos. Frente a los valores de buena conducta que presiden la carta paterna, el presente texto que constituye la respuesta del estudiante se encuentra redactado en términos más concretos, pues en él se da cuenta de su día a día.

Ya, desde las primeras líneas, el estudiante demuestra comprender a la perfección su nuevo estado de distanciamiento físico con respecto a la casa paterna, así como los fines que se derivan del mismo:

Mis queridísimos padres: No pueden figurarse la pena que tengo pensando en Vdes., no pudiéndoles besar cada mañana y cada noche, como lo tenía por costumbre; no pudiendo vivir á su lado en unos meses. Pero comprendo muy bien que la vida en el pueblo es imposible, si he de estudiar una carrera, y me consuela vivir con estos señores, que me quieren y hacen por distraerme cuanto pueden. ${ }^{37}$

La descripción de sus actividades y rutinas no deja de constituir un auténtico relato embellecido de los días cotidianos de un estudiante, como se señala en líneas posteriores. Se observa una educación eminentemente intelectualista, donde se estudia de memoria, pero sin desatender los paseos por el campo dos veces al día, sin que incluso falten las salidas al teatro o al circo. Por supuesto, el comienzo del día se inicia con las oraciones religiosas. Las tareas cotidianas que enumera recuerdan las históricas recomendaciones seleccionadas, en este caso, a partir de los estudios de Alcántara, publicados en 1881 bajo el título Educación intuitiva y lecciones de cosas: "la educación ha de ser integral y completa, $[\ldots]$ a la vez que a la educación del espíritu y en armónica co-

\footnotetext{
36 José María Román y Rufino Cano, «Notas de la formación de maestros», EDUCACIÓN XXI 11 (2008): 73-101.

${ }^{37}$ El Secretario, 34.
} 
rrespondencia con ella, ha de atenderse a la del cuerpo, según ya se expresaba en el Mens sana in corpore sano de Juvenal». ${ }^{38}$

Como añade el profesor de Pedagogía:

al tratarse de la educación del ser humano, hay que tener en cuenta al hombre físico, al hombre intelectual y al hombre moral, es decir al hombre en el niño y en la integridad de su naturaleza, para a un mismo tiempo cuidar de la educación física, intelectual, estética y moral, armonizándolas y equilibrándolas entre sí. ${ }^{39}$

Curiosamente, la presente carta ofrece muestras de la observación de las tres dimensiones, por cuanto el hombre físico es atendido en la vigilancia de los tiempos escolares y en el hábito del paseo en contacto con la naturaleza, la dimensión intelectual se adquiere a través del estudio y la memorización, mientras que la moralidad es examinada a través de la transmisión e interiorización y práctica del credo católico. La descripción de la carta se centra en su mayor totalidad en el relato del horario diario, así como de las actividades correspondientes a los miércoles, domingos y días festivos que ofrecen ocasión para la acotación o el análisis:

Todos los días nos levantamos a las seis, rezamos, nos lavamos, aseamos y desayunamos, y después de rezar otro poquito en clase, á estudiar las lecciones de memoria hasta las nueve, hora en que empiezan las clases, hasta las doce. Comemos, y después a pasear y jugar por el campo hasta las dos ó dos y media. Otra vez luego á clase hasta las cinco, y á esa hora á paseo hasta las siete. Cenamos, estudiamos un rato después, poco tiempo, y á acostar tempranito, menos las noches que vamos al teatro ó circo. ${ }^{40}$

El estudiante describe las rutinas diarias que se inician con las oraciones religiosas, para dar paso al aseo y al almuerzo. Poco tiempo des-

\footnotetext{
${ }^{38}$ Pedro de Alcántara García, Educación intuitiva y lecciones de cosas (Valparaíso: Editorial del Cardo, 1881), 6 .

${ }^{39}$ De Alcántara García, Educación intuitiva y lecciones de cosas, 16.

${ }^{40}$ El Secretario, 35.
} 
pués del inicio del día, las aulas también conceden espacio para nuevos rezos hasta las nueve, hora en la que comienzan las clases, en las que el tiempo se reserva para la memorización de las lecciones; una referencia que refleja la práctica tradicional de la escuela de siempre. Las clases se prolongan durante una jornada partida, pero en el horario cotidiano hay tiempo también para el gozo al aire libre con paseos y juegos por el campo, que es el entorno que rodea al internado, siguiendo la descripción del escolar.

Las excursiones y visitas fuera de las paredes del aula se realizan, según informa el estudiante, a museos, fábricas o talleres; emplazamientos en los que es posible el contacto con los contenidos culturales de la sociedad y en el caso de los establecimientos industriales, permiten aprehender el conocimiento relacionado con la organización económica de la época. En la línea de la educación intuitiva, Alcántara señaló que para enseñar por los ojos son de utilidad los paseos instructivos al campo, a las fábricas, a los monumentos y museos o por extensión, a «los establecimientos de toda clase»; ${ }^{41}$ visitas acompañadas por las debidas explicaciones del maestro. La propia naturaleza constituye en sí misma un agente de educación intuitiva como medio de educación moral -forma de obrar sobre el corazón de los niños y de abrirlo a sus influencias-, intelectual — pues esta es un libro abierto para la investigación y la interrogación, una cadena de escenas instructivas-, y física - pues la naturaleza ofrece todas las buenas condiciones para el desarrollo físico, representadas por el aire libre y saludable o por los templados rayos solares, ${ }^{42}$ una naturaleza asimismo mencionada en las cartas.

Cuando Lorenzo Luzuriaga en las décadas iniciales del siglo xx, describió los principios de la Escuela Nueva extendidos a la enseñanza pública, según Otero en el décimo punto de su ideario, el insigne pedagogo contempló la organización de excursiones, campamentos y colonias. ${ }^{43}$ La corriente de la Escuela Nueva vino a fortalecer los funda-

\footnotetext{
${ }^{41}$ Alcántara García, Educación intuitiva y lecciones de cosas, 116.

42 Alcántara García, Educación intuitiva y lecciones de cosas, 124-126.

${ }^{43}$ Eugenio Otero, «Las teorías educativas en los umbrales de la contemporaneidad», en Teorías e

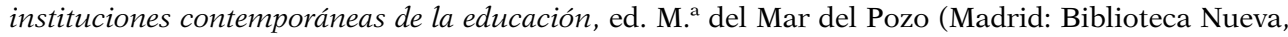
2004), 177-195.
} 
mentos de la pedagogía intuitiva, basada en el principio de actividad del alumno y sustentada por las previas aportaciones pestalozzianas que combinaban actividad intelectual y manual.

Siguiendo a Montero, tanto Johann Heinrich Pestalozzi como Friedrich Froebel asumieron las excursiones en sus modelos escolares -el pedagogo suizo, con excursiones de tarde y durante el período estivalempleadas para la observación directa. Bajo la influencia del naturalismo o el filantropismo, «las excursiones y paseos escolares han sido actividades conocidas, puestas en práctica por los docentes que eran partidarios de la enseñanza activa en España, siendo un signo distintivo de los movimientos de renovación pedagógica», ${ }^{44}$ ya en sus modalidades de excursionismo realista, destinado a la adquisición de ideas, o de excursionismo romántico-nacional. Reguladas en el siglo xx, las excursiones fueron también practicadas por Pablo Montesino -impulsor en España de las Escuelas Normales destinadas a la formación del magisterio, así como de las escuelas de párvulos- aunque el excursionismo fue abiertamente implementado en coincidencia con la labor de la Institución Libre de Enseñanza; en ambos casos, con una visible influencia anglosajona. ${ }^{45}$

Tanto las excursiones al aire libre como las visitas a centros o instituciones externas a la escuela, así como otras actividades pedagógicamente renovadoras, constituyeron un conjunto de tareas que el maestro hubo de distribuir a lo largo del organigrama escolar. Pero durante el período a partir del cual los legisladores de Cádiz formularon las bases del ordenamiento político de la enseñanza, hasta la creación del primer departamento ministerial, ${ }^{46}$ la gestión de los tiempos, en gran parte, fue aquella resultante de la creación empírica desarrollada por los maestros, según Escolano, el maestro hubo de idear los ritmos del proceso, la distribución de las rúbricas curriculares en el horario y la pauta del trabajo o los descansos en el cronosistema; el curso respondía a un

\footnotetext{
${ }_{44}$ Ana M. ${ }^{a}$. Montero, «Los paseos y excursiones escolares: una práctica higiénica de influencias anglosajonas», en Influencias inglesas en la educación española e iberoamericana (1810-2010), ed. José María Hernández Díaz (Salamanca: Universidad de Salamanca, 2011), 251.

${ }^{45}$ Montero, «Los paseos y excursiones escolares», 251-259.

${ }^{46}$ Desde que la Constitución de Cádiz instaura en su artículo 369 la Dirección General de Estudios hasta la creación en 1900 del Ministerio de Instrucción Pública y Bellas Artes, transcurre casi un siglo.
} 
continuo-discontinuo que acogía o eliminaba a los niños en cualquier época del año. En este sentido, el establecimiento en 1887 de la obligatoriedad de las vacaciones escolares supuso una importante innovación..$^{47}$

Tras retomar las últimas palabras del estudiante que se añaden en líneas posteriores, en las que nuevamente se da cuenta del aprovechamiento del entorno natural, se observa una visión poética de la vida campestre y de sus influencias benéficas, de forma que desde una perspectiva pedagógica ciertas frases evocan los párrafos del Emilio de Jean-Jacques Rousseau. En 1762, año de publicación de Emilio o de la educación, el filósofo ginebrino, en sus páginas, afirma preferir la educación en el campo, «lejos de las negras costumbres de las ciudades». ${ }^{48}$ Así, el pensador se prolonga en una explicación más profunda sobre el significado que la naturaleza posee en su plan pedagógico:

Para fortificar el cuerpo y crecer, la naturaleza tiene medios que nunca deben contrariarse. ${ }^{49}$

Observad la naturaleza y seguid la ruta que os marca. Ella ejercita continuamente a los niños; ella endurece su temperamento mediante pruebas de toda especie; ella los enseña desde temprana hora lo que es pena y dolor. [...]. Una vez pasadas esas pruebas, el niño ha ganado fuerzas; y tan pronto como puede usar de la vida, su principio se vuelve más seguro. ${ }^{50}$

En la aldea, un ayo será mucho más dueño de los objetos que quiera presentar al niño; su reputación, sus palabras y su ejemplo tendrán una autoridad que no podrían tener en la ciudad: siendo útil a todo el mundo, todos se apresurarán a complacerle, a ser estimados por él, a mostrarse ante el discípulo tal como el maestro quisiera que fuesen en efecto y, si no se corri-

\footnotetext{
${ }^{47}$ Agustín Escolano, «La cultura de la escuela en España en el entorno de 1900», en Cien años de educación en España. En torno a la creación del Ministerio de Instrucción Pública y Bellas Artes, ed. Pedro Álvarez Lázaro (Madrid: Fundación BBVA, Ministerio de Educación, Cultura y Deporte, 2001), 329-348.

48 Jean-Jacques Rousseau, Emilio o De la Educación (Madrid: Alianza, 1995), 116.

${ }^{49}$ Rousseau, Emilio o De la Educación, 102.

${ }^{50}$ Rousseau, Emilio o De la Educación, 49.
} 
gen del vicio, se abstendrán del escándalo; es cuanto precisamos para nuestro objetivo. ${ }^{51}$

Los párrafos señalados, extraídos de las páginas de Emilio o De la Educación, aluden a los beneficios del espacio natural, al servicio tanto del cumplimiento de los objetivos del educador como del desarrollo de los pupilos, así como a la autoridad y reconocimiento que ciertas figuras de la servidumbre o del servicio consiguen en ese espacio natural, en su relación con el educando.

Rousseau, inspirador de Pestalozzi y Froebel, había integrado el viaje en su pedagogía, como medio de estudio, educación y trabajo; se detectan, en este sentido, sus claras influencias. ${ }^{52}$ La práctica diaria del estudiante se completa algunas noches con visitas al teatro o al circo, si bien las excursiones fuera del recinto educativo se suceden también a mediados de semana y los domingos y festivos; momento del relato en el que se vuelve a hacer referencia a las salidas campestres, mediante su aprovechamiento con juegos, dibujos, pinturas y lecturas. Aparecen así las artes plásticas y la literatura como parte de un ocio útil y provechoso:

Los domingos y días festivos que hace bueno, los pasamos enteros en el campo, disfrutando muchísimo con nuestros juegos, con nuestros dibujos y pinturas, con nuestras lecturas interesantes, en aquellas praderas y bosquecillos, en donde se oye por todas partes correr las fuentes, trinar los pajarillos, silbar las locomotoras. ¡Cuánto me agrada todo esto! ${ }^{53}$

La posición rousseauniana evocada en las páginas de El Secretario desemboca en ciertos influjos de la Escuela Nueva; corriente amplia que contó con el ascendiente del suizo J.H. Pestalozzi, quien incidió en la relevancia de las artes en la educación, pues, como asegura Otero, aquel le atribuyó a la educación estética una importancia extraordinaria, «como condición de una formación moral que tenía claras y peculiares connotaciones religiosas. La educación estética comen-

\footnotetext{
51 Rousseau, Emilio o De la Educación, 116.

52 Montero, «Los paseos y excursiones escolares», 251-259.

53 El Secretario, 35.
} 
zaba por los sentidos», pues se hacía preciso "prestar atención al buen gusto para desarrollar nobles sentimientos». ${ }^{54}$ Sobre la influencia de Pestalozzi en la pedagogía española se han hecho eco, entre otros, Porto Ucha y Vazquez Ramil ${ }^{55}$ o Torrebadella; ${ }^{56}$ según García Hoz, Rufino Sánchez Blanco había publicado Vida y obra de grandes pedagogos, en la cual sobre Pestalozzi se desarrollan tres páginas en su tomo segundo, al mencionarse doscientas obras y opúsculos que lo citan. ${ }^{57}$ Para Sureda, los métodos pestalozzianos simbolizaron una propuesta de renovación, «un intento al que podemos calificar [...] como la inquietud a abrirse a nuevas fórmulas e influencias europeas para renovar la práctica educativa», ${ }^{58}$ conforme a las prácticas asociadas al liberalismo burgués, basadas en la naturaleza infantil, la experimentación de las teorías pedagógicas o la formación del magisterio.

En el conjunto de las actividades referidas en el relato presente, paralelamente, destaca la alusión a la actividad periodística promovida por el maestro, que el escolar señala en el momento en el que explica "porque en el periódico mensual que mi maestro publica, verán ustedes la descripción de una de ellas hecha por mí», ${ }^{59}$ con la oportuna ocasión que se le ofrece para la inclusión de sus propios ejercicios escolares: en este caso, el escolar se refiere a la publicación de una redacción sobre una de las excursiones realizadas.

\section{A MODO DE CONCLUSIÓN}

A través de la descripción y el análisis del contenido de las cartas señaladas, el rastreo de textos de corte epistolar posibilita la discusión de

\footnotetext{
${ }^{54}$ Otero, «Las teorías educativas en los umbrales de la contemporaneidad», 177-195; 190.

${ }_{55}$ Anxo Serafín Porto y Raquel Vázquez Ramil, «El espíritu de Yverdon: influjo de la pedagogía de Pestalozzi en María de Maeztu», en Influencias suizas en la educación española e iberoamericana, ed. José María Hernández Díaz (Salamanca: Ediciones Universidad de Salamanca, 2016), 169-180.

${ }^{56}$ Xavier Torrebadella, «La educación física y el deporte en el contexto ilustrado y liberal de la primera Constitución Española (1800-1814)», Rubrica Contemporanea 4, no. 2 (2013): 73-99, y «Rufino Blanco Sánchez y las fuentes bibliográficas de la Educación Física y el deporte en España», RICYDE. Revista Internacional de Ciencias del Deporte 37, no. 10 (2014): 281-284.

57 Víctor García Hoz, La educación en la España del siglo XX (Madrid: Rialp, 1980).

${ }^{58}$ Bernat Sureda, «Los inicios de la difusión del método de Pestalozzi en España, el papel de los diplomáticos españoles en Suiza y la prensa periódica», Historia de la Educación 4 (1985): 40.

${ }^{59}$ El Secretario, 35.
} 
aspectos e influencias educativas que en un sentido amplio continúan siendo particularmente representativas de una escuela, un tiempo y una sociedad. El contenido de ambas cartas permite la correspondiente reflexión acerca de la forma en la que se muestran las influencias pedagógicas en una sociedad, pues a partir de un modelo de correspondencia decimonónico se procede a un análisis fundamentalmente educativo. Genéricamente, el epistolario representa un manual de correspondencia dirigido a la divulgación de las pautas propias de la escritura epistolar características de los siglos XIX y xx. La utilidad instructiva y educadora de El Secretario, inmersa en el conjunto de publicaciones vinculadas a una finalidad de educación popular y ciudadana, se dirige hacia la resolución de la problemática relacionada con la vida cotidiana. Ambos modelos analizados, relativos a la correspondencia familiar entre padres e hijos, representan un modelo idealizado de los lazos paternos-filiales, articulado sobre los consejos paternos bien acogidos por un hipotético hijo. En relación a la interrogación de partida, es posible identificar ciertas influencias de los nuevos métodos de enseñanza desarrollados pedagógicamente en la vanguardia europea entre desde fines del siglo XIX hasta las primeras décadas del siglo xx, trasladados a España bajo la amplia denominación de Escuela Activa. ${ }^{60}$ Aunque este fue un movimiento de carácter fundamentalmente privado, sus influencias fueron permeables a la educación pública.

En concreto, es en la respuesta del escolar donde la redacción se torna explícita, al señalar un nuevo rol tanto para el alumno como para el profesor que apunta a una nueva metodología en el contexto de la praxis pedagógica tradicional. Por otra parte, las excursiones a las fábricas o talleres, las visitas a museos, al teatro o al circo, así como las salidas al campo, en las que se lee o se dibuja del natural, parecen respon-

\footnotetext{
${ }^{60}$ Ricardo Marín, «Los ideales de la Escuela Nueva», Revista de Educación 242 (1976): 23-42. El grupo escolar Milá y Fontanals, dirigido por Rosa Sensat en Barcelona, fue probablemente el único centro representativo en su conjunto de los requisitos de la Escuela Nueva. Paradójicamente, fueron funcionarios del Ministerio de Instrucción Pública, en su calidad de inspectores como Lorenzo Luzuriaga y Antonio Ballesteros, profesores de Escuelas Normales como Rodolfo Tomás Samper y Margarita Comas, directores de grupos escolares como la citada Rosa Sensat y Pedro A. Gómez Lozano, así como numerosos maestros de educación primaria quienes participaron en la reforma de la educación pública. Entre los Treinta Principios de la Oficina Internacional de las Escuelas Nuevas formulados por Adolphe Ferrière están incluidos los de ser laboratorios de pedagogía práctica, la búsqueda de una pedagogía integral, el contacto con la naturaleza y las observaciones a partir de la misma, así como de las industrias y organizaciones sociales o la práctica de los viajes.
} 
der a esa nueva pedagogía que vence las barreras tradicionales de las cuatro paredes del aula para obtener beneficio de unas nuevas posibilidades instructivas y lúdicas en el entorno próximo. Se inicia una nueva forma de abordar las disciplinas tradicionales, tanto como la oportunidad para una nueva forma de relación del alumnado con el entorno y con sus compañeros, así como también de un nuevo carácter en la relación maestro-alumno; la palabra del maestro y el manual de texto dejan de ser los únicos centros de interés a partir de los cuales articular la práctica pedagógica.

Paralelamente, en los dos modelos analizados el interés por el desempeño escolar y por los resultados en la instrucción del «estudiantillo», junto con su buena conducta, radica la posibilidad de movilidad social, constitutiva en la sociedad intuida, de oportunidades de mejora y ascenso social. La educación, por lo tanto, se muestra en una de sus funciones más clásicas.

Los modelos epistolares analizados representan una particular simbiosis de las características propias de una sociedad tradicional - el contexto de fondo de las cartas- con una incipiente pedagogía que tímidamente asoma en una sociedad jerarquizada y conservadora.

\section{Nota sobre la autora}

Alicia Díaz Balado es docente del Departamento de Pedagoxía e Didáctica de la Universidade de Santiago de Compostela (USC); habiéndose doctorado en la mencionada universidad en el año 2009. Entre el período 20062008 fue becaria de colaboración en el proyecto de investigación y documentación histórico-educativa del Museo Pedagóxico de Galicia (MUPEGA).

\section{REFERENCIAS}

Alliaud, Andrea. Los maestros y su historia. Buenos Aires: Granica, 2007.

Badanelli, Ana María y Kira Mahamud. «Entre la ruptura y la continuidad de esquemas socioemocionales en los libros de lectura». Historia y Memoria de la Educación 2 (2015): 125-160. 
Barquín, Javier. «La investigación sobre el profesorado. Estado de la cuestión en España». Revista de Educación 306 (1995): 7-65.

Barreiro, Herminio. «Orixes institucionais da educación pública europea». Sarmiento. Revista Galega de Educación 110 (2007): 117-129.

Braida, Ludovica. «Los libri di lettere en el siglo XVI. Un género editorial entre el disenso religioso y la difusión del "buen vulgar"». En Cinco siglos de cartas. Historia y prácticas epistolares en las épocas moderna y contemporánea, editado por VV.AA., 97-122. Huelva: Universidad de Huelva. Publicaciones, 2014.

Castillo, Antonio. «Me alegraré de que al recibo de ésta...». Cuatrocientos años de prácticas epistolares (siglos XVI a XIX)». Manuscrits 29 (2011): 19-50.

De Alcántara, Pedro. Educación intuitiva y lecciones de cosas. Valparaíso: Editorial del Cardo, 2003.

El Secretario (sin año de edición). Burgos: Hijos de Santiago Rodríguez.

Escolano, Agustín. «Textos científicos y didácticos utilizados en las escuelas técnicas en la segunda mitad del siglo XVIII y principios del XIX». Historia de la Educación 4 (1985): 385-395.

Escolano, Agustín. «Los manuscritos escolares». En Historia Ilustrada del libro escolar en España, editado por Agustín Escolano, 343-371. Madrid: Fundación Germán Sánchez Ruipérez, 1997.

Escolano, Agustín. «Libros para la escuela. La primera generación de manuales escolares». En Historia Ilustrada del libro escolar en España, editado por Agustín Escolano, 19-46. Madrid: Fundación Germán Sánchez Ruipérez, 1997.

Escolano, Agustín. «La cultura de la escuela en España en el entorno de 1900». En Cien años de educación en España. En torno a la creación del Ministerio de Instrucción Pública y Bellas Artes, editado por Pedro Álvarez Lázaro, 329-348. Madrid: Fundación BBVA, Ministerio de Educación, Cultura y Deporte, 2001.

Escolano, Agustín. «La recepción de los modelos de la Escuela Nueva en los manuales de comienzos del siglo Xx». Historia de la Educación 25 (2006): 317-340.

García Hoz, Víctor. La educación en la España del siglo XX. Madrid: Rialp, 1980.

Gold, Hazel. «Una postdata imprescindible: cartas y epistolarios en el canon literario del siglo XIX». En La elaboración del canon en la literatura española del siglo XIX: II Coloquio de la Sociedad de Literatura Española del Siglo XIX (Barcelona, 20-22 octubre de 1999), editado por VV.AA., 185-194. Barcelona: Universitat, Promociones y Publicaciones Universitarias, 2002.

Gómez de Mier, José Eusebio. El comerciante español ó epistolario comercial con modelos de contabilidad y documentos mercantiles, la traducción de las 
frases de difícil inteligencia, una fraseología infantil en español y alemán, un vocabulario de los términos más usados en el comercio y nomenclatura de los artículos más corrientes, en ambas lenguas, las abreviaturas más usuales en la correspondencia española y un suplemento en latín, alemán y español conteniendo las principales drogas medicinales. Hamburgo: Imprenta de J.J. Nobiling, 1854.

Gómez Hernández, José Antonio. «La preocupación por la lectura pública en España: las bibliotecas "populares". De las Cortes de Cádiz al plan de bibliotecas de María Moliner». Revista General de Información y Documentación 2, no. 3 (1993): 55-94.

Kalman, Judith. «El acceso a la cultura escrita: la participación social y la apropiación de conocimientos en eventos cotidianos de lectura y escritura». Revista Mexicana de Investigación Educativa 17, no. 8 (2003): 37-66.

Marín, Ricardo. «Los ideales de la Escuela Nueva». Revista de Educación 242 (1976): 23-42.

Martínez Cuadrado, Miguel. La burguesía conservadora (1874-1931). Madrid: Alianza, 1973.

Montero, Ana M. ${ }^{\mathrm{a}}$. «Los paseos y excursiones escolares: una práctica higiénica de influencias anglosajonas». En Influencias inglesas en la educación española e iberoamericana (1810-2010), editado por José María Hernández Díaz, 251-259. Salamanca: Universidad de Salamanca, 2011.

Morales, José. «Maestros y discípulos». SCHRIPTA THEOLOGICA 37, no. 2 (2005): 607-215.

Olmos, Miguel A. «Sobre lectores "populares” y lectura común en España (1870-1936)». Dicenda. Cuadernos de Filología Hispánica 22 (2004): 183199.

Otero, Eugenio. «Las teorías educativas en los umbrales de la contemporaneidad». En Teorías e instituciones contemporáneas de la educación, editado por M. ${ }^{a}$ del Mar del Pozo Andrés, 177-195. Madrid: Biblioteca Nueva, 2004.

Pérez-Díaz, Víctor. «Maestros y discípulos. Algunas causas culturales e institucionales de la debilidad de la universidad española contemporánea». ASP Research Papers 106 (a) (2012): 1-13. Consultado el 25 de abril de 2016. www.asp-research.com/sites/default/files/pdf/Asp106.pdf

Porto, Anxo Serafín y Raquel Vázquez Ramil. «El espíritu de Yverdon: influjo de la pedagogía de Pestalozzi en María de Maeztu». En Influencias suizas en la educación española e iberoamericana, editado por José María Hernández Díaz, 169-180. Salamanca: Ediciones Universidad de Salamanca, 2016.

Román, José María y Rufino Cano. «Notas de la formación de maestros». EDUCACIÓN XXI, no. 11 (2008): 73-101.

Rousseau, Jean-Jacques. Emilio o De la Educación. Madrid: Alianza, 1995. 
Sánchez-Redondo, Carlos. "Política e ideología en los libros de lectura escolares en la escuela primaria de los años sesenta». En El libro escolar, reflejo de intenciones políticas e influencias pedagógicas, editado por Alejandro Tiana, 115-133. Madrid: UNED, 2008.

Serrano, Carmen. "Secretarios de papel”: Los manuales epistolares en la España Moderna (siglos XVI-XVII)». En Cinco siglos de cartas. Historia y prácticas epistolares en la época moderna y contemporánea, editado por VV.AA., 77-96. Huelva: Universidad de Huelva, Servicio de Publicaciones.

Sierra, Verónica. Aprender a escribir cartas. Los manuales epistolares en la España contemporánea (1927-1945). Gijón: Trea, 2003.

Sierra, Verónica. «iCuidado con la pluma! Los manuales epistolares en el siglo xx». Litterae: Cuadernos de cultura escrita 3, no. 4 (2003): 281-325.

Sierra, Verónica. "As Cartas e a Escola" los manuales epistolares para niños en la España del siglo xx». História da Educaçao 16, no. 2 (2004): 59-77.

Sierra, Verónica. Cartas presas. La correspondencia carcelaria en la Guerra Civil y el Franquismo. Madrid: Marcial Pons, Editorial Complutense, 2016.

Steiner, George. Lecciones de los maestros. México: Siruela, Fondo de Cultura Económica, 2004.

Sureda, Bernat. «Los inicios de la difusión del método de Pestalozzi en España, el papel de los diplomáticos españoles en Suiza y la prensa periódica». Historia de la Educación 4 (1985): 35-62.

Torrebadella, Xavier. «La educación física y el deporte en el contexto ilustrado y liberal de la primera Constitución Española (1800-1814)». Rubrica Contemporanea 4, no. 2 (2013): 73-99. Consultado el 15 de marzo de 2017. https://dialnet.unirioja.es/servlet/articulo?codigo $=5036568$

Torrebadella, Xavier. «Rufino Blanco Sánchez y las fuentes bibliográficas de la Educación Física y el deporte en España». RICYDE. Revista Internacional de Ciencias del Deporte 37, no. 10 (2014): 281-284. Consultado el 1 de mayo de 2017. doi: 10.5232/ricyde 